\title{
Corrosion behavior of steel in biodiesel of different origin
}

\author{
Ancaelena-Eliza STERPU*a ${ }^{* a}$ Anca Iuliana DUMITRU ${ }^{\mathrm{a}}$ and Mihai-Florinel POPA ${ }^{\mathrm{b}}$ \\ ${ }^{a}$ Department of Chemistry and Chemical Engineering, "Ovidius" University of Constanta, 124Mamaia Blvd, \\ 900527 RO Constanta, Romania \\ b “Auto Axel” Ltd., W. Maracineanu Str, No. 7, Postal code: 700373 - Iaşi, Romania
}

\begin{abstract}
This study aims to characterize the corrosion behavior of steel by static immersion tests in biodiesel obtained from three different types of vegetable oils (sunflower oil, rapeseed oil and corn oil) at room temperature for 49 days. At the end of the test, corrosion behavior was investigated by weight loss measurements and changes in physical and chemical properties of biodiesel. Biodiesel samples were analyzed to investigate density, dynamic viscosity, acidity index, refractive index and saponification index. Results showed that under the experimental conditions, steel was more susceptible to corrosion in biodiesel from corn oil as compared to biodiesel from sunflower oil and rapeseed oil.
\end{abstract}

Keywords: carbon steel, biodiesel, sunflower, rapeseed, corn oil.

\section{Introduction}

Biodiesel is an alternative diesel fuel derived from renewable feed stock such as plant or animal fats. It is renewable, biodegradable, non toxic and has almost very close property to that of diesel fuel.

Although, the acceptance of biodiesel in automobile applications is relatively a successful story, questions continue to arise with regards to its corrosive nature and degradation of fuel properties. The fuel system in modern automotive diesel engine includes many precision parts which are made from different ferrous or nonferrous alloys. Though these parts are quite corrosion resistant, corrosion damage of fuel system parts is accelerated considerably when the fuel becomes oxidized or absorbs moisture from air. Comparing with diesel, biodiesel is more prone to absorb water, causes microorganism contamination and also allows the development of electrochemical corrosion processes. The water got condensed on the metal surface and promoted the rate of corrosion. Water provoqued microbial growth and corroded the fuel system components. Water can also cause hydrolysis of biodiesel that is composed of esters to fatty acids, furthering corrosive. The water content in biodiesel can convert the fatty acid alkyl esters (biodiesel) to fatty acids through a reversible reaction. The oxidative behavior of biodiesel enhances corrosion and wear of engine parts in contact with biodiesel [1].

There is a number of studies available in the literature related to corrosion of different metals in biodiesel. Kaul et al. [2] investigated the corrosiveness of different biodiesel (i.e. Jatropha curcas, Karanja, Mahua and Salvadora) as compared to that of diesel fuel. They found that biodiesel from Jatropha curcas and Salvadora were more corrosive for both ferrous and non-ferrous metal. Geller et al. [3] conducted immersion test in fat based biodiesel for different ferrous and non-ferrous metals. They observed that copper alloys were more prone to corrosion in biodiesel as compared to ferrous alloys. These studies show that fuel properties such as density and viscosity were also changed a lot due to the metal contact. Thus, biodiesel upon exposure of different metals not only shows its aggressive corrosiveness but also undergoes degradation in fuel properties.

The presence of high levels of unsaturated fatty acid methyl esters (FAME) makes biodiesel very susceptible to oxidation as compared to petroleum diesel. According to some studies [4] during oxidation process, the fatty acid methyl ester usually 
forms a radical next to double bond and then quickly bonds with the oxygen from air. This process may change the fuel properties including viscosity, total acid number, density, iodine value, pour point, cloud point etc. Increased acidity and peroxide value as a result of oxidation reactions can also cause the corrosion of fuel system components, hardening of rubber components and fusion of moving components.

\section{Experimental}

Corrosion behavior of carbon steel in biodiesel was investigated by static immersion test at room temperature $\left(25-30^{\circ} \mathrm{C}\right)$. Immersion tests in biodiesel obtained from three different types of vegetable oils (sunflower oil, rapeseed oil and corn oil) were carried out for $1176 \mathrm{~h}$ (49 days). 3 test coupons of carbon steel $\left(0.21 \%\right.$ wt. carbon; density $\left.7.85 \mathrm{~g} / \mathrm{cm}^{3}\right)$ of size $40 \times 10 \times 2 \mathrm{~mm}$ were made by machining and polishing. Before immersion, the coupons were cleaned with detergent and distilled water and then were degreased by acetone. Before and after exposing the test coupons into different test fuels, weight was measured by a balance with four decimal accuracy. Biodiesel samples were analyzed to investigate density, dynamic viscosity, acidity index (acid number) (ASTM D664), refractive index (ASTM D 1218) and saponification index (ASTM D 94) for every 7 days during the immersion test period to estimate degradation of fuel properties in time. The density and viscosity are simultaneously measured using an Anton Paar device, SVM 3000 type. At the end of the test, extent of corrosion was investigated by corrosion rate measurements and changes in surface morphology. The obtained data from weight loss were converted into corrosion rate (mm/year) using Eq. (1) [2].

$$
\text { Corrosion_rate }=\frac{\text { Wt.loss } \times 87600}{\text { Area_(ime_netal_density__ }}
$$

where:

wt. loss in g, area in $\mathrm{cm}^{2}$ of metal surface exposed time in hours exposed density is in $\mathrm{g} / \mathrm{cm}^{3}$.

\section{Results and Discussions}

The process of corrosion in steel is not very clear and data differ. Steel is an alloy composed mostly of iron and has a carbon content ranging from 0.2 to $2.1 \%$ by weight. The carbon content in the steel could be a reason for its high resistance to corrosion due to the fact that carbon has a high corrosion resistance. However, Prieto et al. [5] reported that biodiesel is more conductive electrically compared to gasoline and petrodiesel and may cause galvanic metal corrosion in steel. Corrosion of metal and metal alloys varies with feedstock used for synthesis of biodiesel. This is due to differences in the chemical composition of the feedstock showing various degrees of corrosiveness.

The static immersion test was conducted for 49 days at room temperature, which varied between 20 to $25^{\circ} \mathrm{C}$, and corrosion rate (mm/year) was determined. Weight losses resulting from corrosion in sunflower, rapeseed and corn biodiesel were 0.9, 0.8 and $1.2 \mathrm{mg}$, respectively.

The corrosion rates of carbon steel coupons exposed to biodiesel from three different types of oils at room temperature are shown in Fig. 1.

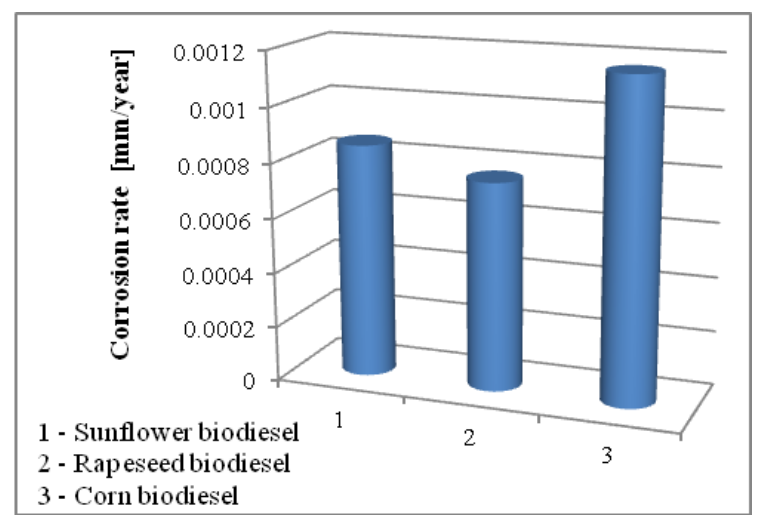

Fig.1. The corrosion rates values of carbon steel coupons exposed to biodiesel from three different types of oils at room temperature

The present study shows that at room temperature, corrosion rates for carbon steel in sunflower, rapeseed and corn biodiesel are $0.000855 \mathrm{~mm} /$ year, $0.000760 \mathrm{~mm} / \mathrm{year}$ and $0.001164 \mathrm{~mm} /$ year respectively. 
Table 1. The measured values of dynamic viscosity of biodiesel at different exposure time

\begin{tabular}{|c|c|c|c|}
\hline \multirow{2}{*}{$\begin{array}{c}\text { Exposure } \\
\text { time } \\
{[\mathrm{h}]}\end{array}$} & $\begin{array}{c}|c| \\
\text { Sunflower } \\
\text { biodiesel }\end{array}$ & Rapeseed biodiesel & Corn biodiesel \\
\hline 0 & 7.6678 & 5.9468 & 6.3726 \\
\hline 168 & 7.6751 & 5.9545 & 6.394 \\
\hline 336 & 7.6802 & 5.9554 & 6.4443 \\
\hline 504 & 7.7354 & 5.9662 & 6.445 \\
\hline 672 & 7.8266 & 5.9681 & 6.4463 \\
\hline 840 & 7.8281 & 5.9681 & 6.4611 \\
\hline 1008 & 7.8366 & 5.9752 & 6.4716 \\
\hline 1176 & 7.8423 & 5.981 & 6.4931 \\
\hline
\end{tabular}

These results suggest that the corrosion rate of carbon steel in corn biodiesel is higher as compared to sunflower biodiesel and rapeseed biodiesel.

Pitting corrosion was also observed after several days of immersion test starting.

The measured values of dynamic viscosity of different biodiesel types during the static immersion test period are presented in Table 1.

The variation of density, acidity index, refractive index and saponification index of different biodiesel type (before and after exposing to carbon steel coupons at room temperature) vs. exposure time are shown in figures. 2, 3, $\mathbf{4}$ and $\mathbf{5}$ respectively.
Viscosity is the most important property of biodiesel since it affects the operation of fuel injection equipment, particularly at low temperatures when the increase in viscosity affects the fluidity of the fuel. High viscosity leads to poorer atomization of the fuel spray and less accurate operation of the fuel injectors.

Density is another important property of biodiesel. Fuel injection equipment operates on a volume metering system, hence a higher density for biodiesel results in the delivery of a slightly greater mass of fuel.

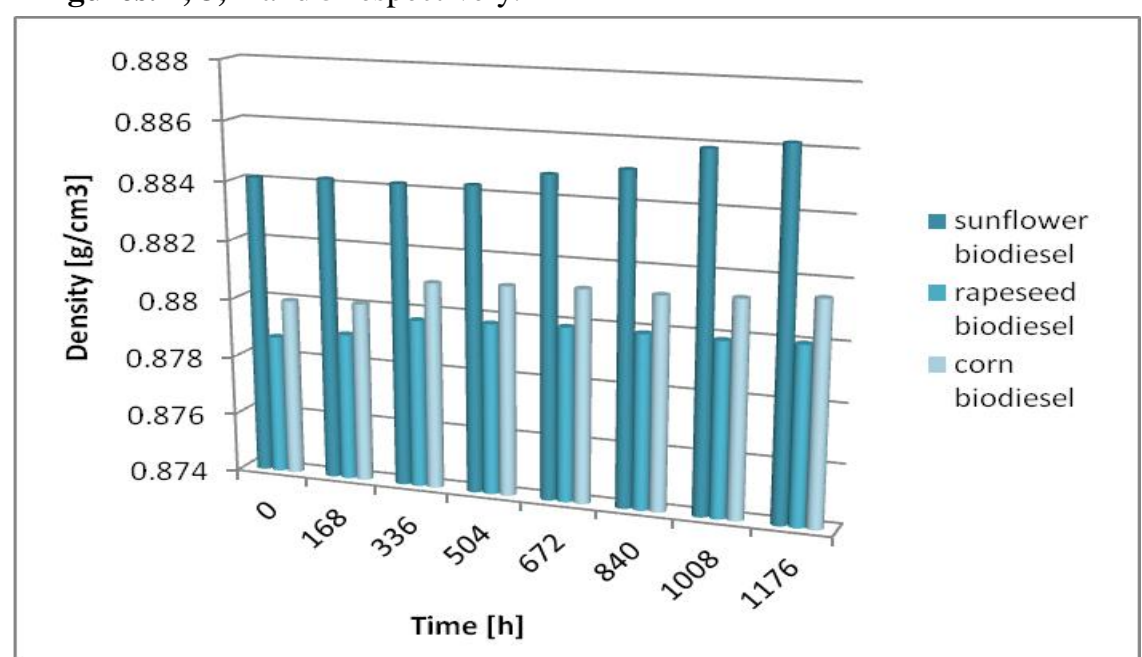

Fig.2. Change in biodiesel density with increasing exposure time at room temperature 


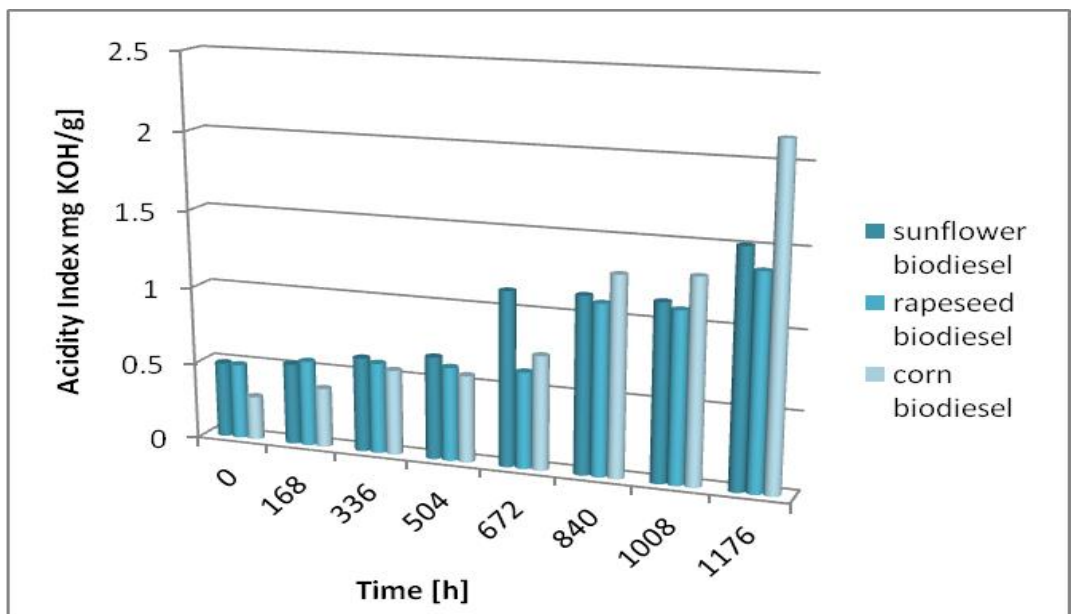

Fig.3. Change in biodiesel acidity index with increasing exposure time at room temperature degradation while the fuel is in service. For biodiesel, the standard calls for a maximum acid number of $0.80 \mathrm{mgKOH} / \mathrm{g}$. The entire sample's acid numbers were well below the specified limits before static immersion test. The increase of acid number is mainly due to the increase in amount of free fatty

An increase in density from 848 to $885 \mathrm{~g} / \mathrm{L}$ for biodiesels corresponds to an increasing of the viscosity from 2.8 to $5.1 \mathrm{cSt}$ and the increases are highly regular [6].

The acid number is a measure of the amount of acidic substances in a fuel under the conditions specified by this standard. The acid number can acids that are present in oil. provide an indication of the level of lubricant

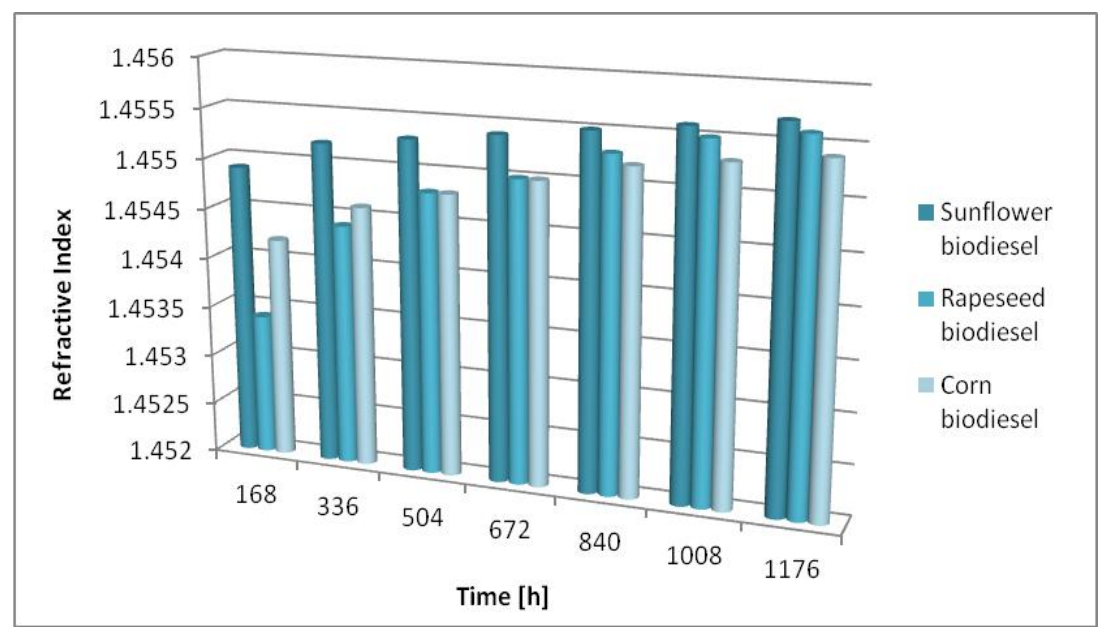

Fig.4. Change in biodiesel refractive index with increasing exposure time at room temperature 


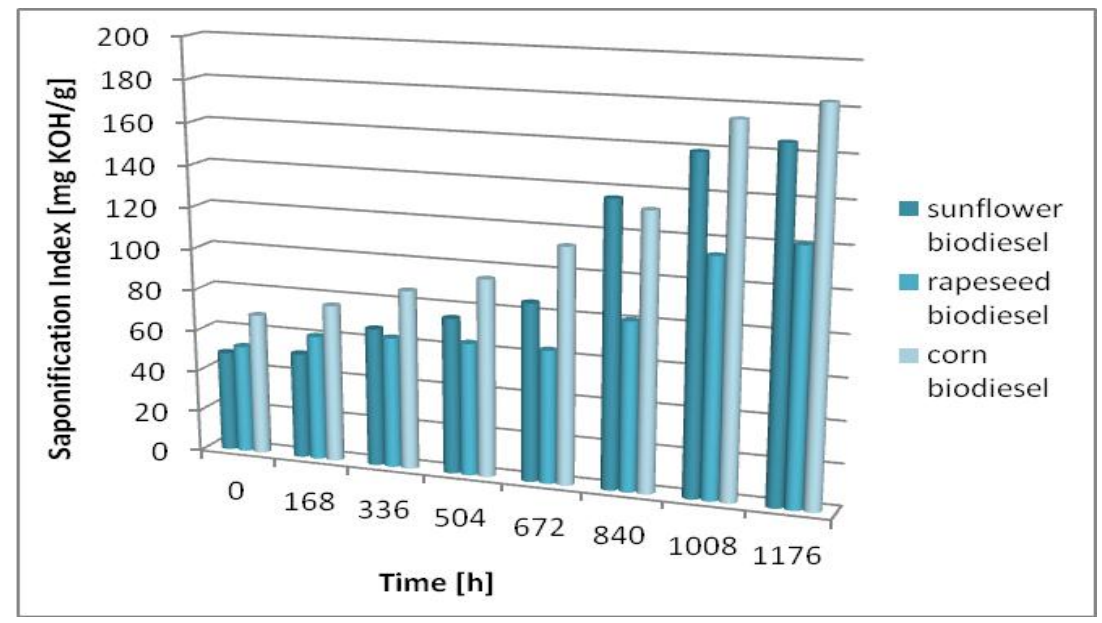

Fig.5. Change in biodiesel saponification index with increasing exposure time at room temperature

Commercially available crude oils and fats contain considerable amount of free fatty acids that react with the alkaline catalyst and form saponified products during base catalyzed transesterification requiring further purification of the products. The saponification not only consumes the alkali catalyst but also the resulting soaps can cause the formation of emulsions which create difficulties in downstream recovery and purification of the biodiesel.

From the results shown in Figs.2-5, it is notable that biodiesel produced from sunflower, rapeseed and corn oil exposed to carbon steel samples showed significant degradation, as evidenced by increased density, dynamic viscosity, acidity index, refractive index and saponification index.

\section{Conclusions}

Alternative fuels such as biodiesel raise the issue of corrosion in CI engine parts that come into contact with the fuel.

Corrosion behavior of biodiesel produced from sunflower, rapeseed and corn oil was estimated during static immersion test for 1176 hours (49 days). Corrosiveness of biodiesel depends on its feedstock.
The present study shows that at room temperature, carbon steel coupons were more susceptible to corrosion in biodiesel from corn oil as compared to biodiesel from sunflower oil and rapeseed oil. The weight loss in biodiesel from corn oil is with $33 \%$ higher than sunflower biodiesel and with $40 \%$ than rapeseed biodiesel. Similar observations were also made for corrosion rate (mm/year).

The density values of biodiesel samples slowly increase during the static immersion test. The corrosion process did not caused significant degradation of biodiesel viscosity. Moreover, the dynamic viscosity value was almost constant during the static immersion test period which is given in Table 1.

Exposure of biodiesel to carbon steel caused significant degradation in the fuel, as evidenced by increased acidity number, refractive index and saponification index, which led to increased corrosion. This can also be attributed to water condensation or dissolution of more oxygen into the fuels from the atmosphere which can produce different types of fatty acids ultimately accelerating the corrosion rate.

All types of biodiesel exhibited an increase in acidity index and saponification index but it is more pronounced in the case of biodiesel from corn oil as 
compared to biodiesel from sunflower oil and rapeseed oil. The increase in refractive index is more pronounced in the case of rapeseed biodiesel comparing to sunflower and corn biodiesel.

\section{References}

* E-mail address: asterpu@ univ-ovidius.ro

[1]. J. Janaun and N. Ellis, Renewable and Sustainable Energy Reviews, 14 1312-1320 (2010).

[2]. S. Kaul, R.C. Saxena, A. Kumar, M.S. Negi and A.K. Bhatnagar, Fuel Processing Technology 88, 303-307 (2007).
[3]. Geller D.P., Adams T.T., Goodrum J.W. and Pendergrass J., Fuel 87, 92-102, (2008).

[4]. Sarin A., Arora R., Singh N.P., Sharma M. and Malhotra R.K., Energy 34, 1271-1275, (2009).

[5]. Prieto L., Sorichetti P.A. and Romano S.D., International Journal of Hydrogen Energy 33, 3531-3537, (2008).

[6]. Demirbas A., Fuel 86, 92-102, (2007).

Submitted: July $16^{\text {th }} 2012$ Accepted in revised form: 30.10.2012 